\title{
Agency Problems and Commitment in Delegated Bargaining*
}

\author{
Hongbin $\mathrm{Cai}^{\dagger}$ \\ Department of Economics \\ UCLA
}

\author{
Walter Cont \\ Department of Economics \\ Universidad Nacional de La Plata and FIEL
}

\begin{abstract}
In the context of (one-sided) delegated bargaining, we analyze how a principal (a seller) should design the delegation contract in order to provide proper incentives for her delegate (an intermediary) AND gain strategic advantage against a third party (a buyer). We consider situations in which there are both moral hazard and adverse selection problems in the delegation relationship and where the seller tries to gain strategic advantage by imposing a minimum price above which she pays the delegate a commission. It is shown that incentives and commitment are substitutes. A low type agent is given less discretion in dealing with the buyer and weaker incentives, while a high type agent is given more discretion and stronger incentives.
\end{abstract}

JEL Codes: C78, D82, L14

Key Words: delegation, bargaining, incentives, commitment

\footnotetext{
*We are grateful to the co-editor and two anonymous referees for very constructive comments and suggestions. We also would like to thank Alberto Bennardo, Sushil Bikhchandani, Colin Campbell, Ken Corts, Bryan Ellickson, Ben Klein, Phillip Leslie, David Levine, Joe Ostroy, John Riley, Jean-Laurent Rosenthal, Lars Stole, Guofu Tan, Earl Thompson, Lixin Ye, Bill Zame, and seminar participants at University of British Columbia, UCLA, Rutgers University, Universidad Nacional de La Plata and Universidad de San Andrés for very helpful comments. The first author gratefully acknowledges support from the National Science Foundation. All remaining errors are our own.

${ }^{\dagger}$ Corresponding author: Hongbin Cai, Department of Economics, UCLA, 405 Hilgard Ave, Los Angeles, CA 90095-1477, e-mail:cai@econ.ucla.edu, telephone: 30-794-6495, fax: 310-825-9528.
} 


\section{INTRODUCTION}

Consider a seller of indivisible goods, e.g., an owner of a car dealership, who sells her products to consumers with unit demand whose valuations are unknown to the seller. Unable to price discriminate among such consumers, standard textbook economics tells us that the seller is left with only one option - monopoly pricing — if she can commit to a posted price. However, this is not how cars are usually sold in the United States. Car dealerships, and sellers of many other goods, hire sales managers and sales people to do the actual selling. Hiring sales people is costly, not only because they have to be paid wages for their work but also because there often exist various agency problems between the sellers and their sales staff (such as moral hazard, adverse selection or combinations of both). Why are sales people still useful? One important reason is that they learn about consumers' valuations and bargain with them over a price. ${ }^{1}$ This is a case of delegated bargaining, namely, the principal (seller) hires a delegate (salesperson) to bargain with third parties (consumers). Such arrangements naturally raise the question: how should the seller construct the optimal delegation contract? In the standard principal-agent literature, the agent's actions directly determine the principal's expected payoff, so the game the agent is hired to play with other parties is suppressed. Our focus in this paper is on how considerations of the bargaining games between the delegate and consumers affect the seller's contract design.

Specifically, we study the following one-sided delegation game. A risk-neutral seller of one indivisible good hires a risk-neutral delegate to sell the good for her. They sign a delegation contract. At the time the contract is signed, neither the seller nor the delegate knows the valuation held by the (potential) buyer but they know its distribution. ${ }^{2,3}$ The delegate meets a

\footnotetext{
${ }^{1}$ Another important reason is that salesmen can specialize in reducing search costs for the sellers, but this does not seem to be important for situations such as car salesmen. Here we abstract from search cost considerations.

${ }^{2}$ The model applies equally to one potential buyer with the distribution of valuations and to a population of buyers with the identical distribution of valuations. We use the single buyer case for ease of exposition.

${ }^{3}$ If the seller knew the buyer's exact valuation before she signed a contract with the delegate, then she could achieve "full commitment" by using a "target contract" (e.g., Fershtman et al. (1991), Kahenmann (1995)). A target contract requires the delegate to obtain a certain price for the good, otherwise he is paid nothing or may even face some penalty. Without uncertainty, the seller could set the price target exactly equal to the buyer's valuation, which commits the delegate to get this price, leaving the buyer and the delegate with no surplus. However, if the seller knew the buyer's valuation, she could achieve the identical outcome without the delegate by way of perfect price discrimination (i.e., setting a posted price equal to the buyer's valuation).
} 
buyer and learns about the buyer's valuation. They then bargain over a price. If the delegate and the buyer reach an agreement, the buyer receives the good and makes payment, and the delegate delivers the payment to the seller, who then pays him according to their contract. The seller only observes the sale revenue the delegate brings back to her.

In our model there are both moral hazard and adverse selection problems in the delegation relationship. We suppose that the delegate exerts sales effort that is not observable to the seller. Furthermore, delegates can differ in their disutility of effort, which is also not observable to the seller. Hence the delegation contract needs to provide incentives for the delegate to exert proper efforts and to reveal his true type to the seller. In addition, the seller imposes a minimum price to gain strategic advantage against the buyer. We assume that delegation contracts are observable to potential buyer and cannot be renegotiated. ${ }^{4}$ Restricting attention to linear sharing contracts, we derive the seller's optimal minimum price schedule and optimal commission rate schedule jointly. We find that commitment through minimum prices and incentives for the delegate are substitutes for the seller. That is, higher (lower) minimum prices are associated with weaker (stronger) incentives for the delegate and hence lower (higher) effort by the delegate. As a result, a lower type agent (who has higher disutility of effort) is given less discretion (a higher minimum price) and weaker incentives (a lower commission rate), while a higher type agent (who has lower disutility of effort) is given more discretion in making deals with customers (a lower minimum price) and are held responsible for the outcomes to a greater degree (a higher commission rate).

The intuition for these results is as follows. A minimum price can give the delegate an advantage in bargaining with the buyer because it raises the delegate's threat point. With a standard bargaining model, it can be shown that the higher the minimum price, the higher the final sales price, provided that the buyer's valuation is higher than the minimum price. On the other hand, a higher minimum price means that the delegate and the buyer will fail to reach a deal with a greater probability. If provided with proper incentives, a high type delegate can get a larger share of the joint surplus and hence a higher price, holding fixed the buyer's valuation and the minimum price. Consequently, for a high type delegate, the marginal cost of raising the minimum price is higher since the consequences of loss of trade fall disproportionately on

\footnotetext{
${ }^{4}$ See discussions about not-perfectly-observable contracts and renegotiable contracts in Section 5 .
} 
the delegate and the seller. Therefore, for a high type delegate, the seller should have a greater commission rate and a lower minimum price so she can take advantage of his greater bargaining power; for a low type delegate, the seller should offer a smaller commission rate and impose a greater minimum price so she can take greater advantage of the commitment effect.

The insights of our model can be useful in understanding incentive contracting in real world applications. For example, it is common in the literature to estimate incentive intensity for managers by estimating how sensitive managers' incomes are to changes in firm values or profits. In the seminal paper by Jensen and Murphy (1990), they report the famous finding that "CEO wealth changes $\$ 3.25$ for every $\$ 1,000$ change in shareholder wealth." This and similar findings of subsequent works are used to show that pay performance sensitivities are low in the corporate world. Such a low level of pay performance sensitivities can be consistent with the standard agency theory only if CEOs are sufficiently risk-averse. It is also suggested that the evidence of low incentive intensity implies severe conflicts of interests between managers and shareholders. ${ }^{5}$ However, our model suggests an additional factor that can possibly play a role in the evidence on pay performance sensitivities. It is well known that compensation contracts for managers can be used as a commitment instrument to gain competitive advantages in the marketplace, see, Fershtman and Judd (1987a, b). In light of our model, one way to achieve commitment is to set high performance targets and let managers' incentive pays depend on how much their firms' performances exceed the targets. ${ }^{6}$ If that is the case, then changes in firm values or profits can only result in small variations in managers' incentive pays, especially when performance targets are set high. However, this does not mean that managerial incentives are necessarily low and managers are not acting in the interests of shareholders. To the contrary, it can well be that because of the commitment power in high performance targets, managers compete aggressively in the marketplace to the benefits of their shareholders.

Our model can also shed light on contract designs in real life situations involving delegated bargaining. For example, in car dealerships, "most salesmen are paid a commission which is usually 25-30\% of the gross profit (based on dealer invoice, not incentives) on every car they

\footnotetext{
${ }^{5}$ See Murphy (1999) for a comprehensive survey.

${ }^{6}$ An important source of pay performance sensitivities comes from stock options, which have built in performances targets through exercise prices (Murphy (1999)).
} 
sell." (Eskeldson (1997, p.46)) To us, the most interesting part of the agency contracts for car salesmen is the sum on which the commission is based. In the standard principal agent model, the optimal contract requires commissions to be based on the seller's profit, i.e., sales revenue minus the seller's cost. However, in the U.S. car dealership business, the real cost of a car to the dealer is usually not its invoice price. Car manufacturers typically offer dealers "holdbacks", which rebate the dealers a few percent of the invoice prices when cars are actually sold. In addition to dealer holdbacks, car manufacturers offer many other kinds of incentives (such as dealer rebates, volume discounts, credit discounts, etc.) that may vary from time to time and from dealership to dealership. ${ }^{7}$ With all these provisions from car manufacturers taken into account, the real cost of a car for the dealer is substantially lower than its invoice cost. Since car salesmen's commissions are calculated on the basis of invoice prices rather than on dealer cost, car salesmen will not be willing to sell cars for less than invoice prices. Since the invoice prices in the car dealership example are equivalent to the minimum prices in our model, our analysis provides an explanation for using invoice prices instead of the seller's profit in calculating commissions.

Since Schelling (1960), it has long been recognized that the principal may gain strategic advantages against a third party by properly designing a contract for the agent. A large amount of subsequent work has investigated the conditions under which this commitment effect can arise and its implications in various economic situations. ${ }^{8}$ Our paper belongs to this large literature. It differs from most of the existing papers in that we take as given the commitment effect of delegation contracts, and concentrate our attention on the interactions between agency problems and commitment considerations in optimal contract design.

Fershtman and Judd (1987b) present the first model that studies how optimal contracts should respond to both agency problems and commitment considerations. They consider a

\footnotetext{
${ }^{7}$ Many car-buying guide books (e.g., Eskeldson (1997)) and websites offer information about car prices. Buyers can easily get car invoice prices from car-related web sites such as Edmunds.com or the Kelley Blue Book's Web site, KBB.com, as well as information on manufacturers-to-dealer incentives and promotions.

${ }^{8}$ See, e.g., Vickers (1985), Fershtman and Judd (1987a,b), Sklivas (1987), Dewatripont (1988), Gal-Or (1991a, 1992, 1995), Fershtman, Judd and Kalai (1991), Katz (1991), Hermalin (1992, 1995), Caillaud, Jullien and Picard (1995), Martimort (1996), Baye, Crocker and Ju (1996), Laffont and Martimort (1997), Fershtman and Kalai (1997), Corts and Neher (2003), Kockesen and Ok (2003).
} 
double-sided delegation game in which two managers are hired by their owners to compete with each other in an oligopolistic situation. In their model, like ours, delegation contracts are public information and not renegotiable. Unlike in our model, there is only a moral hazard problem in the delegation relationship and the owners are more risk-averse than the managers are (so without commitment considerations, the owners should optimally sell the firms to the managers). Fershtman and Judd show that to take advantage of the commitment power of the delegation contracts, the owners "over-compensate" the managers for success and thus bear more risk than is efficient. ${ }^{9}$ Caillaud et al. (1995) analyze a duopolistic competition model with double sided delegation in the presence of both agency problems and commitment. Their model has only adverse selection (action is contractible) and delegation contracts are renegotiable. They show that public but renegotiable delegation contracts still have commitment effects because they impose restrictions on the possible renegotiation outcomes in the presence of asymmetric information.

In our model, the delegate and the buyer bargain under complete information, and yet sometimes fail to reach agreements because the delegate is pre-committed by the seller to bargain aggressively all the time. ${ }^{10}$ This is closely related to Haller and Holden (1997), who show that a heterogeneous group of people sometimes want to impose a super-majority ratification rule on the bargaining outcomes their delegate reaches with a third party in order to gain strategic advantage. As a result, an agreement that is beneficial from the perspective of the median voter may fail to be reached. The main difference between Haller and Holden (1997) and our paper is that while they focus on intra-group heterogeneity among the principals, we focus on the agency problems in the delegation relationship. Crawford (1982) formulated the idea that commitment by bargainers in the presence of uncertainty can lead to bargaining failures, but he abstracted from the commitment instruments bargainers use. ${ }^{11}$

\footnotetext{
${ }^{9}$ In fact, the incentives for the managers are so strong that an owner is better off if her manager fails.

${ }^{10}$ That strategic delegation causes distortions is not new. For example, in oligopolistic competition, Fershtman and Judd (1987) show that strategic delegation leads to lower prices and lower profit but greater social surplus if oligopolists compete in Cournot fashion, but the opposite is true if they compete in Bertrand fashion (see also Baye, Crocker and Ju (1996) and Vickers (1986)).

${ }^{11}$ Studying a variation of Crawford (1982), Muthoo (1996) shows that without uncertainty about costs of revoking commitments, the bargaining outcome is efficient. In another related paper, Cai (2000) shows that the
} 
Our paper is also related to the literature on vertical restraints. That literature is mainly concerned with how upstream firms can manage or affect downstream competition to increase profits by means such as exclusive territories or resale price maintenance (see, e.g., Rey and Tirole, (1986)). ${ }^{12}$ One interpretation of our model is that of an upstream firm (the seller) designing a contract for a downstream firm (the delegate). However, we focus on the seller's strategic consideration of gaining bargaining advantage against potential buyers, while the literature on vertical restraints is interested in how to manage downstream competition. For one example of the differences, one can think of invoice prices as car manufacturers' instrument of resale price maintenance, but it does not explain why salesmen's commissions depend on sale prices minus invoice prices rather than dealers' real costs.

The rest of the paper is organized as follows. In Section 2, we present the model. Then Section 3 analyzes how the delegate's efforts and the seller's delegation contracts affect the equilibrium outcome of the bargaining game between the delegate and the buyer. Section 4 solves for the seller's optimal minimum price and commission rate schedule, and derives the model's implications. In Section 5, we discuss issues concerning the linearity of contracts, as well as some of the factors that affect whether and how the minimum price can be credibly used as a commitment device to give the delegate bargaining advantage.

\section{THE MODEL}

The model consists of three parties: a seller (P), a delegate (D), and a buyer (B). The seller hires the delegate to sell a good to the buyer. The cost of the good to the seller is normalized to zero. The delegate's reservation utility is $U_{0}$. At the time the seller contracts with the delegate, neither knows the buyer's valuation for the good. Their belief about the valuation is given by a

agency problems in the delegation relationship can cause bargaining inefficiency. Specifically, in Cai's model, a delegate bargains with a third party under complete information but faces reelection after the bargaining outcome becomes known to his constituency (principals). In this case, delay in reaching agreements can be used by the delegate as a signal to his principals that he is of "good type". In contrast to Cai (2000), the agency problems in the delegation relationship do not directly cause bargaining inefficiency in our model. Rather, bargaining failures are caused by the seller's strategic manipulation of the delegation contract that commits the delegate to bargain aggressively.

${ }^{12}$ Optimal contracting between one manufacturer and one retailer is also studied in this literature, see, e.g., Gal-Or (1991b). 
probability distribution $G(s)$ with an everywhere positive density function $g(s)$, where $s \in[\underline{s}, \bar{s}]$ $(0 \leq \underline{s}<\bar{s})$ is the buyer's valuation.

Once hired by the seller, the delegate exerts sales effort $e$ that affects the division of the total trade surplus between the seller and the buyer. The way in which $e$ affects the seller's share will be specified later. The delegate incurs an effort cost of $C(e, t)$, where his "type", $t$, characterizes his disutility of effort. We make the following standard assumptions on $C(e, t)$ : (i) $C(e, t)$ is strictly increasing and convex in $e, C_{e}=\partial C / \partial e>0$ and $C_{e e}=\partial^{2} C / \partial e^{2}>0$; and (ii) higher types have lower effort costs and lower marginal effort costs, that is, $C_{t}=\partial C / \partial t<0$ and $C_{e t}=\partial^{2} C / \partial e \partial t<0$. For simplicity, we also assume that $C_{e e t}=0$ and $C_{e t t} \geq 0$.

The seller does not observe either the delegate's effort $e$ or his type $t$, so the delegation relationship suffers from both moral hazard and adverse selection. At the time the seller contracts with the delegate, the seller knows that the delegate's type is drawn from a distribution function $F(t)$ with density function $f(t)>0$ for every $t \in[\underline{t}, \bar{t}]$, the domain of $t$. We make the standard assumption that $F(t)$ has the monotone hazard rate property: $f(t) /[1-F(t)]$ is increasing in $t$.

All three players are assumed to be risk-neutral. If the buyer's valuation is $s$, then the total trade surplus is $s$ since the seller's cost is zero. Suppose the delegate obtains $x$ (i.e., the agreement price is $x$ ) for the seller, and the seller pays the delegate a wage of $w$. Then the seller's utility is $U_{P}=x-w$, the delegate's utility is $U_{D}=w-C(e, t)$, and the buyer's utility is $U_{B}=s-x$.

The timing of the game is as follows. At date 0, the seller offers a menu contract to a delegate. The delegate chooses a contract, which becomes observable and non-renegotiable. At date 1 he chooses an effort level $e$. At date 2, the delegate meets a buyer, and they bargain over a price. Finally, once a deal is reached, the delegate gives the revenue of the sale to the seller, who then pays the delegate according to the contract. The seller can only observe the agreement price, so the contract she offers the delegate can be contingent on the price only.

For simplicity, we assume that bargaining is conducted under complete information. That is, the delegate learns the buyer's valuation of the good and the buyer learns the delegate's effort and hence his bargaining power before they bargain over a price. ${ }^{13}$ Since the delegate acquires

\footnotetext{
${ }^{13}$ More realistically, the buyer's valuation and the delegate's bargaining power are likely to be revealed during the bargaining process. But unfortunately, there are no tractable models of bargaining under incomplete information
} 
information about the buyer's valuation only after contracting with the seller, the seller cannot design a mechanism that uses reports by both the delegate and the potential buyer to elicit the buyer's valuation. ${ }^{14}$

For concreteness, we adopt the bargaining game of Binmore, Rubinstein and Wolinsky (BRW) (1986) to model the negotiation process between the delegate and the buyer. It is well-known that this game is isomorphic to the standard alternating-offer bargaining game of Rubinstein (1982) and both are closely related to the cooperative solution concept of the Nash Bargaining Solution, ${ }^{15}$ hence the results of this paper are not specific to the particular bargaining game we use. In this bargaining game, the delegate and the buyer take turns making offers. Without loss of generality, suppose the delegate makes the first offer. The buyer can respond with either "accept" or "reject". If an offer is accepted, they reach an agreement and the game ends. If an offer is rejected, there is a small exogenous probability that bargaining will break down, in which case the total surplus disappears. Let $\rho_{d}$ and $\rho_{b}$ be the probability of bargaining breakdown following a rejection by the delegate and the buyer, respectively. If a party rejects but bargaining does not break down, then the two parties continue bargaining in the next round. The bargaining game could conceivably last indefinitely if no agreement is ever reached or breakdown never occurs. Of course, with probability one the bargaining game will end in finite time with either an agreement or a breakdown because of the positive probabilities of bargaining breakdown.

In the BRW game, the division of the joint surplus depends on $\rho_{d}$ and $\rho_{b}$. These in turn depend on factors such as the length of time the parties can make a counter-offer after rejecting the opponent's offer and how well they can control the bargaining process (e.g., mental toughness of not losing control of one's temper in confrontational situations). In this bargaining game, we suppose that $\rho_{d}$ is decreasing in the delegate's effort $e$. The idea is that the harder working

in the existing bargaining literature.

${ }^{14}$ We rule out the possibility that the delegate and the buyer can collude against the seller. In some cases, reputation concerns of the delegate or legal constraints may help control collusive behavior of the delegate. In others, collusion between the delegate and the buyer is a real concern for the seller. This is certainly an interesting issue to analyze in future research, but it is beyond the scope of this paper.

${ }^{15}$ See Osborne and Rubinstein (1990) for discussions about the link between non-cooperative alternating-offer bargaining games and the Nash Bargaining Solution. 
delegate will be more diligent in processing and making offers quickly or will work to gain better control over the bargaining process. We will be more specific about how $e$ affects $\rho_{d}$ in the next section when we analyze how the delegate's effort choice and the seller's delegation contract affect equilibrium outcomes.

Before turning to the bargaining outcome, we present a benchmark case in which the seller simply uses a posted price to sell the good without hiring a delegate. Whether or not the seller will want to hire a delegate depends on the cost of hiring him and the additional expected gain he can obtain for the seller. Apart from the benchmark case, we assume for simplicity, without deriving the formal conditions, that the seller finds it worthwhile to hire the delegate. ${ }^{16}$

\section{Benchmark Case: Standard Monopoly Pricing without a Delegate}

Suppose the seller can commit to a posted price. The optimal posted price for the seller, $\tau$, maximizes the expected profit

$$
\max _{\{\tau\}} E U_{P}=\int_{\tau}^{\bar{s}} \tau d G(s)=\tau[1-G(\tau)]
$$

So $\tau$ is given by

$$
1-G(\tau)=\tau g(\tau)
$$

This is the standard monopoly pricing formula. The intuition is simple. Consider raising $\tau$ by $\Delta \tau$. This leads to an increase in the expected revenue of $[1-G(\tau)] \Delta \tau$, where $1-G(\tau)$ is the probability that the buyer has a valuation above $\tau$ and is still willing to buy. The cost of increasing $\tau$ by $\Delta \tau$ is that the seller loses a revenue of $\tau$ when the buyer has a valuation just equal to $\tau$, which occurs with a probability of $g(\tau) \Delta \tau$. So Equation (1) simply says that the optimal posted price should be set at a level such that the marginal benefit of raising it equals to its marginal cost.

\section{BARGAINING OUTCOMES AND COMMITMENT}

\footnotetext{
${ }^{16}$ It is clear that the seller will be more likely to hire the delegate if $(1)$ the delegate's reservation utility $U_{0}$ is smaller; or (2) the delegate is more effective (either because of his endowed bargaining ability or bargaining power acquired through extra effort).
} 
In this section we analyze how the equilibrium outcome of the bargaining game between the delegate and the buyer is affected by the delegate's effort and the seller's delegation contract. To isolate these effects, we first consider a hypothetical situation in which the delegate owns the good and bargains directly with the buyer. We suppose that the delegate's effort $e$ reduces the probability of bargaining breakdown following his rejection, $\rho_{d}$, in the following way. Let us suppose that $\rho_{d}$ is proportional to $\rho_{b}$ and $\rho_{d}=k(e) \rho_{b}$, where $k(e)+1=1 /\left(r_{0}+r^{\prime} e\right)$ and both $r_{0}$ and $r^{\prime}$ are positive parameters whose values ensure that $r_{0}+r^{\prime} e \leq 1$. So $\rho_{d}$ is decreasing and convex in $e$. Since the length of time it takes to make an offer is typically very short in many applications (e.g., negotiations in car dealerships that include many offers and counter-offers usually conclude within hours), it is reasonable to suppose that both $\rho_{b}$ and $\rho_{d}$ are sufficiently close to zero. Thus we consider the limit case as $\rho_{b}$ and $\rho_{d}$ approach zero. The lemma below follows from the standard result from Binmore et al. (1986):

Lemma 1 Suppose that the delegate acts as the seller and the buyer's valuation is $s$. As $\rho_{b}$ and $\rho_{d}$ go to zero, the bargaining outcome in the unique subgame perfect equilibrium is such that the delegate and the buyer reach an agreement without delay and the agreement price is $x=r s$, where $r=r_{0}+r^{\prime} e$.

Proof: By Binmore et al. (1986), this bargaining game always has a unique subgame perfect equilibrium. In the equilibrium, the two parties reach an agreement in the first round, and the delegate's share of the joint surplus is $\rho_{b} /\left[1-\left(1-\rho_{b}\right)\left(1-\rho_{d}\right)\right]$. Taking the limit as $\rho_{b} \rightarrow 0$, we have $r=1 /(1+k(e))=r_{0}+r^{\prime} e$.

Q.E.D.

By Lemma 1, the delegate's effort reduces $\rho_{d}$ and thus increases his share of the joint surplus in the bargaining outcome. For simplicity, we assume that the delegate's equilibrium share $r$ is linear in $e$. The results of the paper will not be affected qualitatively if $r$ is concave in $e\left(r^{\prime \prime} \leq 0\right)$. Since $r=r_{0}+r^{\prime} e, r_{0}$ represents the delegate's share of the bargaining outcome if he exerts no extra effort, and $r^{\prime}$ measures how effective his extra effort is in improving his bargaining ability and hence his share of the joint surplus.

Now we examine the effects of delegation contracts on the bargaining outcome. Consider first the case in which the seller offers the delegate a straightforward linear contract, $w(x)=\alpha+\beta x$, where $\alpha$ is an up-front fixed wage, $\beta>0$ is the commission rate, and $x$ is the price (which is 
also the profit since the cost is normalized to zero). With this linear contract, the delegate's preference is just an affine transformation of $u_{d}=x$ (i.e., the delegate owns the good and sells it for himself). It is well known that the equilibrium outcome of the bargaining game between the delegate and the buyer will not be affected at all by such an affine transformation, see, Binmore et al. (1986), and Osborne and Rubinstein (1990). Thus, with a linear delegation contract $w(x)=\alpha+\beta x$, the delegate will reach an agreement with the buyer at a price $x=r s$ as given by Lemma 1 . Then he will be paid $w(x)$ according to the contract, and the seller gets a net profit of $x-w(x)$. So the linear delegation contract $w(x)=\alpha+\beta x$ has no effect on the bargaining outcome: the delegate and the buyer will reach the same deal as if the delegate owned the good and sold it for himself.

A simple way the seller can achieve commitment is to modify the linear delegation contract by imposing a minimum price. Minimum prices seem to be a commonly observed practice (e.g., in car dealerships), and our analysis attempts to shed light on their use in connection with an optimal provision of incentives in delegation contracts. Specifically, we consider the following class of contracts. If the delegate makes a deal at a price of $x$, his wage is

$$
w(x)=\alpha+\beta(x-z)
$$

where $z$ is a minimum price that the seller wants the delegate to obtain. If he does not sell the good, his wage is $\alpha$ (i.e., $\alpha$ is an up-front payment). According to this contract, the seller pays the delegate $\alpha$ once they sign the contract. The delegate then bargains with a buyer over a price. If the delegate brings back more than $z$, then the seller pays him a commission at a rate of $\beta$ of what the delegate obtains in excess of the minimum price $z$. Otherwise, if the delegate brings back less than $z$, then he has to pay the seller the amount $\beta(z-x) .{ }^{17}$ If the delegate does not strike a deal with the buyer, there is neither bonus nor penalty.

The bargaining outcome under this contract is reported in the following Lemma.

Lemma 2 Suppose the delegation contract is given by Equation (2) and the delegate exerted effort $e$. When $s \geq z$, the unique equilibrium outcome of the bargaining game is an immediate agreement with a price of $x=r(e)(s-z)+z$. When $s<z$, there will be no agreement.

\footnotetext{
${ }^{17}$ Any amount of penalty for a sale price below the minimum price will have the same effect. As long as there is penalty, the delegate is better off not selling than selling below the minimum price.
} 
Proof: When $s<z$, there is no way the delegate can get a positive commission from a deal without leaving the buyer worse off than not buying, so there will be no agreement in this case. Suppose $s \geq z$. Following the standard arguments of bargaining theory, we show that there is a unique subgame perfect equilibrium. Let $v_{d}$ and $V_{d}$ be the infimum and supremum of the delegate's equilibrium payoffs. Define $v_{b}$ and $V_{b}$ similarly for the buyer. Then the following must be true: (1) $v_{d} \geq \beta\left[s-\left(1-\rho_{b}\right) V_{b}-z\right]$, namely, the delegate can ensure an acceptance by the buyer if he offers $\left(1-\rho_{b}\right) V_{b} ;(2) V_{d} \leq \beta\left[s-\left(1-\rho_{b}\right) v_{b}-z\right]$, namely, the delegate cannot make the buyer accept an offer less than $\left(1-\rho_{b}\right) v_{b} ;(3) v_{b} \geq s-\left(1-\rho_{d}\right) V_{d} / \beta-z$, namely, the buyer can ensure the delegate's acceptance if he can get a payoff of $\left(1-\rho_{d}\right) V_{d}$ (which means a price of $\left.\left(1-\rho_{d}\right) V_{d} / \beta+z\right)$; and $(4) V_{b} \leq s-\left(1-\rho_{d}\right) v_{d} / \beta-z$, namely, the buyer cannot make the delegate accept an offer that gives him a payoff less than $\left(1-\rho_{d}\right) v_{d}$ (which means a price of $\left.\left(1-\rho_{d}\right) v_{d} / \beta+z\right)$. From (1) and $(4), v_{d} \geq \beta(s-z) \rho_{b} /\left[1-\left(1-\rho_{b}\right)\left(1-\rho_{d}\right)\right]$. From (2) and (3), $V_{d} \leq \beta(s-z) \rho_{b} /\left[1-\left(1-\rho_{b}\right)\left(1-\rho_{d}\right)\right]$. Therefore, $v_{d}=V_{d}=\beta(s-z) \rho_{b} /\left[1-\left(1-\rho_{b}\right)\left(1-\rho_{d}\right)\right]$. That is, the unique equilibrium price is $x=r(s-z)+z$, where $r=\rho_{b} /\left[1-\left(1-\rho_{b}\right)\left(1-\rho_{d}\right)\right]$. In the unique equilibrium, the delegate offers $x$ in the first round and the buyer accepts. By Lemma 1 , as $\rho_{b} \rightarrow 0, r$ goes to $r(e)=r_{0}+r^{\prime} e$.

Q.E.D.

Lemma 2 shows both the commitment power of the delegation contract with a minimum price and its potential cost. When $s \geq z$, compared with Lemma 1 , the agreement price increases by an amount of $(1-r(e)) z$ as a result of imposing a minimum price of $z$. This commitment benefit is larger when the minimum price $z$ is set higher, as long as it is not too high so as to prevent a deal. The key to this result is that the delegate has to get at least $z$ on behalf of the seller in order to be paid a bonus. So the "real" joint surplus he and the buyer can bargain over is $\tilde{s}=s-z$, of which the delegate gets a share of $r(e)$, given their relative bargaining power. The potential cost of using a minimum price as a commitment device is that the seller may set the minimum price so high that it prevents the delegate from reaching a deal with the buyer. This is the case when $s<z$.

Note that if the seller sets a minimum price $z \in[0, \underline{s}]$, then for any possible $s$ the delegate and the buyer will reach a deal. Since commitment comes without cost for $z \in[0, \underline{s}]$, the seller should seek the maximum amount of commitment in this range, thus the optimal $z$ should be 
in $[\underline{s}, \bar{s}]$. As we will see in the next section, the seller will in general set an optimal $z$ that is strictly above $\underline{s}$.

\section{INCENTIVES AND COMMITMENT}

In this section we study the seller's optimal delegation contract (or mechanism) taking into account both agency problems and the commitment effect. By the revelation principle, it is without loss of generality to focus on direct revelation mechanisms in which the delegate is provided proper incentives to reveal his type truthfully and choose the effort level the seller desires. In a direct revelation mechanism, a seller's mechanism consists of a wage schedule $(\alpha(\hat{t}), \beta(\hat{t}))$, a minimum price $z(\hat{t})$, and a recommendation of effort level $e(\hat{t})$, all depending on the delegate's announced type $\hat{t}$. Given the seller's mechanism, an type $t$ delegate chooses an announcement of type $\hat{t}$ and an effort level to maximize his expected utility. The seller's mechanism design problem can be stated as

$$
\max _{\{\alpha(t), \beta(t), e(t), z(t)\}} E U_{P}=\int_{\underline{t}}^{\bar{t}}\left\{\int_{z(t)}^{\bar{s}}[x-\beta(t)(x-z(t))] d G(s)-\alpha(t)\right\} d F(t)
$$

subject to:

(i) $(t, e(t)) \in \operatorname{argmax}_{\{\hat{t}, e\}} U_{D}=\alpha(\hat{t})+\beta(\hat{t}) \int_{z(\hat{t})}^{\bar{s}}(x-z(\hat{t})) d G(s)-C(e, t)$.

(ii) $U_{D}(t) \geq U_{0}, \forall t$.

(iii) $x=\left(r_{0}+r^{\prime} e\right)[s-z(t)]+z(t)$, for $s \geq z(t)$, and 0 otherwise.

Condition (i) is the incentive compatibility constraint for the delegate, which states that he finds it optimal to report his true type and to choose the recommended level of effort. The interim participation constraint (condition (ii)) requires that the optimal contract has to ensure the delegate at least his reservation utility. Condition (iii) describes the bargaining outcome given by Lemma 2 for every possible buyer's valuation.

Let $e^{*}(t)$ and $z^{*}(t) \in(\underline{s}, \bar{s})$ be the solution to the following first-order conditions:

$$
\begin{aligned}
r^{\prime} \int_{z^{*}}^{\bar{s}}\left[s-z^{*}\right] d G(s) & =C_{e}\left(e^{*}, t\right)-\left[\frac{1-F(t)}{f(t)}\right] C_{e t}\left(e^{*}, t\right) \\
\left(1-r\left(e^{*}\right)\right)\left(1-G\left(z^{*}\right)\right) & =z^{*} g\left(z^{*}\right)
\end{aligned}
$$


Let $\alpha^{*}(t)$ and $\beta^{*}(t)$ in contract (2) be such that:

$$
\begin{aligned}
\alpha^{*}(t) & =C\left(e^{*}(t), t\right)-\int_{\underline{t}}^{t} C_{t}\left(e^{*}(\nu), \nu\right) d \nu-\frac{C_{e}\left(e^{*}(t), t\right)}{r^{\prime}} r\left(e^{*}(t)\right)+U_{0} \\
\beta^{*}(t) & =\frac{C_{e}\left(e^{*}(t), t\right)}{r^{\prime} \int_{z^{*}(t)}^{\bar{s}}\left[s-z^{*}(t)\right] d G(s)}
\end{aligned}
$$

The following proposition characterizes the seller's optimal mechanism.

Proposition 1 The linear contract with fixed wage $\alpha^{*}(t)$ and commission rate $\beta^{*}(t)$, the minimum price $z^{*}(t)$, and the recommended effort $e^{*}(t)$ consist of a solution to the optimal mechanism design program of Equation (3).

Proof: See the Appendix.

The optimal mechanism of Proposition 1 is easy to understand. Equation (4) says that the marginal benefit of effort on the left-hand side equals the marginal cost of effort on the right-hand side. The marginal benefit of effort is the marginal increase in the delegate's share of the joint surplus $\left(r^{\prime}\right)$ times the expected joint surplus between the delegate and the buyer, and the marginal cost of effort consists of the direct effort cost to the delegate $C_{e}(e, t)$ and the information rent $C_{e t}[1-F(t)] / f(t)$. Note that the marginal benefit of effort is affected by the minimum price $z^{*}$ : higher $z^{*}$ reduces the probability of sale (i.e., probability of $s \geq z^{*}$ ) and the actual joint surplus between the delegate and the buyer $s-z^{*}$ when $s \geq z^{*}$.

Equation (5) says that the optimal minimum price should balance the marginal benefit with the marginal cost of raising the minimum price. Like Equation (1), the right-hand side of Equation (5) can be thought as the marginal expected loss of sales from raising the minimum price. The left-hand side of Equation (5) represents the marginal increase of expected gain to the seller from raising $z$. Given the minimum price $z, 1-G(z)$ is the probability of a successful sale. However, when there is a successful sale, the marginal value of one dollar increase in $z$ gives the seller an additional revenue of $1-r(e)$, not 1 dollar. The reason is that without the increase in the minimum price, the delegate gets a share of $r(e)$ of the increase in sale price in bargaining with the buyer. Thus, compared with Equation (1), the marginal benefit of raising the minimum price is smaller. Of course, the optimal effort and minimum price interact with each other in both Equations (4) and (5) and must be determined jointly. 
Comparing Equation (5) with Equation (1), one can easily see that the seller's optimal minimum price $z^{*}$ must be smaller than the optimal posted price $\tau$. In addition, the greater the delegate's bargaining power (namely, $r$ ), the larger the difference between the optimal posted price $\tau$ and the optimal minimum price. When the delegate has zero bargaining power $(r=0)$, then the minimum price coincides with the optimal posted price. In this case, the delegate does not bring in additional sales revenue to the seller. On the other hand, when the delegate's bargaining power is very large ( $r$ approaches one), the optimal minimum price goes to $\underline{s}$, and trade is almost efficient. In this case, the final sale price is close to the buyer's valuation, so the trade outcome resembles, up to the agent costs, that of a perfectly discriminating monopolist. In general, when the delegate has positive but not full bargaining power, the trade outcome under delegated bargaining falls in between posted-price selling and perfectly discriminating monopoly pricing. Perfectly discriminating monopoly pricing requires that the monopolist knows every buyer's valuation and can commit to a take-it-or-leave-it price offer to buyers. When the buyer's valuation is not observed, as an alternative to posted-price selling, this paper considers delegated bargaining whereby the seller hires a delegate to find out the buyer's valuation and bargain over a price. This trading mechanism removes some of the rigidity in posted-price selling, so the use of the delegate improves trade efficiency. Since the minimum price decreases in the delegate's bargaining power, the efficiency gain associated with the use of delegate is increasing in his bargaining power. Of course, whether the seller gets more profit by hiring the delegate relative to posted-price selling depends not only on the delegate's bargaining power, but also on the cost of hiring him and the distribution of the buyer's valuation. ${ }^{18}$

The next proposition shows the relationship between the optimal effort and minimum price.

Proposition 2 In the seller's optimal mechanism, the optimal effort level $e^{*}(t)$ is non-decreasing in the delegate's type, and the optimal minimum price $z^{*}(t)$ is non-increasing in the delegate's type. Therefore, higher type delegates are given more discretion in bargaining and work harder than lower types.

Proof: See the Appendix.

The key to understanding Proposition (2) is that commitment through minimum price and

\footnotetext{
${ }^{18}$ Wang (1995) compares seller self-bargaining with posted-price selling in a different model.
} 
the delegate's effort are substitutes for the seller. An easy way to see this is through the bargaining outcome equation $x=r(e)(s-z)+z$. Clearly, the marginal revenue of effort decreases in the minimum price $z$. From Equations (4) and (5), the marginal benefit of $e^{*}$ is decreasing in $z^{*}$ and the marginal benefit of $z^{*}$ is decreasing in $e^{*}$. More formally, one can see that the seller's expected payoff function (Equation (11) in the Appendix) $E U_{P}(e,-z, t)$ is supermodular in $(e,-z, t)$. By the monotone comparative statics (see Milgrom and Shannon (1994)), $e^{*}(t)$ and $-z^{*}(t)$ must be non-decreasing in $t$. Intuitively, Proposition 2 says that since it is relatively easier to induce a more able (higher type) delegate to work hard and get a good price, the seller will impose a smaller minimum price for him to take advantage of his large bargaining power and hence benefit from more successful transactions. Conversely, it is more costly to provide incentives for a less able (low type) delegate to work hard and get a good price, so the seller will impose a greater minimum price to take advantage of the commitment effect.

Below we derive several implications of the model.

Corollary 1 In the seller's optimal contract, the commission rate $\beta^{*}(t)$ is non-decreasing and the fixed wage $\alpha^{*}(t)$ is non-increasing in the delegate's type.

Proof: See the Appendix.

This corollary says that under the seller's optimal contract, a more able delegate (who is less effort averse) is provided stronger incentives through a greater commission rate along with a smaller fixed wage than a less able one.

Suppose $C(e, t)=c_{0}+0.5 \mu e^{2}+\gamma e[\bar{t}-t]$, where $c_{0}, \mu$, and $\gamma$ are all positive parameters. Here $\mu$ measures how difficult it is to motivate the delegate, and $\gamma$ measures the degree (or importance) of asymmetric information between the seller and the delegate.

Corollary 2 The minimum price $z^{*}(t)$ decreases in the delegate's (endowed) relative bargaining power $r_{0}$, and increases when the delegate is more difficult to motivate (larger $\mu$ ) or when asymmetric information between the seller and the delegate is more severe (larger $\gamma$ ). The commission rate $\beta^{*}(t)$ moves in the opposite direction.

Proof: See the Appendix.

In our model, the only source of inefficiency is a failure to trade. Suppose that the buyer's valuation is distributed uniformly in $[\underline{s}, \bar{s}]$. The likelihood of no trade occurring is simply $(z-$ 
$\underline{s}) /(\bar{s}-\underline{s})$, and the expected loss is $0.5\left(z^{2}-\underline{s}^{2}\right) /(\bar{s}-\underline{s})$, both of which increase with $z$. From Proposition 2, it follows that a more able delegate has a smaller probability of bargaining failure. Corollary 2 then implies the following:

Corollary 3 The probability of bargaining failure and its associated welfare loss decrease when the delegate's (endowed) relative bargaining power, $r_{0}$, is larger, and increase when the delegate is more difficult to motivate (larger $\mu$ ) or when asymmetric information between the seller and the delegate is more severe (larger $\gamma$ ).

These results may lead to some testable implications. Take car dealerships as an example. As discussed before, invoice prices can be interpreted as the minimum prices in this case. To apply our model to car dealerships, a small discrepancy needs to be resolved first. In the model, the seller's cost is normalized to zero, and the seller's optimal minimum price and compensation contracts vary according to the model's parameters. In reality, for cars of the same model and year, invoice prices are set by the manufacturer and are uniform for all dealerships, but their real costs differ from dealerships to dealerships. To resolve this discrepancy, note that what is important for commitment is how much minimum prices exceed the seller's real cost. ${ }^{19}$ Thus we can measure the degree of commitment in the car dealership case by the differences between the invoice prices and the dealer's real costs. The main result of the paper that commitment and incentives are substitutes would suggest the following hypotheses: (i) across dealers of the same brand of cars (e.g., Ford dealers), lower cost dealerships (hence high commitment) will tend to have lower commission rates for their salesman while holding other factors fixed; and (ii) across sales people of similar models (e.g., Ford Escape and Toyota RAV4), sales people for cars with higher invoice prices will tend to have lower commission rates after controlling for real costs and other factors. The comparative statics results of the model in Corollaries 2 and 3 suggest other empirical tests once proper proxies of the model's parameters are available. For example, one may expect that consumers have less access to alternative sellers and thus smaller bargaining power against the sales people in some markets and more in others, e.g., an auto dealership in a small city in Midwest versus that in a metropolitan area such as Los Angeles. Such geographic differences could therefore proxy for $r_{0}$.

\footnotetext{
${ }^{19}$ The relevant range of consumers' valuations in a large population is from the seller's real cost to some maximum valuation $\bar{s}$.
} 


\section{DISCUSSION}

\subsection{Linear versus Non-linear Contracts}

In order to study the interaction between agency problems and commitment in the simplest possible setting, we focus in this paper on delegation contracts that are linear in sales prices above the minimum price. This is mainly motivated by the observation that contracts with linear structures are commonly used in real life. In addition to fixed wages, salesmen typically earn commissions as certain percentages of sales revenue (e.g., real estate agents) or sale revenue in excess of fixed targets (e.g., car salesmen). ${ }^{20}$ Incentives for managers (e.g., profit-sharing and bonuses) are also usually in some (piece-wise) linear form. On a practical level, contracts with linear structures are simple and easy to implement. Theoretically, a number of papers have shown that linear contracts are optimal in various settings, see, e.g., Laffont and Tirole (1986), McAfee and McMillan (1987) and Holmstrom and Milgrom (1987). In our model, the contract presented in Proposition 1 is optimal, under the condition (iii) of Equation (3) that for given $e$ and $z$, the bargaining outcome is $x=\left(r_{0}+r^{\prime} e\right)(s-z)+z$, for $s \geq z$, and 0 otherwise (see the proof of Proposition 1 in the Appendix). That is, for any contract with a minimum price $z$, if the delegate gets a sales price of $x=\left(r_{0}+r^{\prime} e\right)(s-z)+z$ for $s \geq z$ after exerting effort $e$, then this contract cannot give the seller an expected payoff strictly greater than what she can get under the contract presented in Proposition 1.

One possibility we rule out is that the seller may gain further bargaining advantage against the buyer by using non-linear contracts. For example, one can imagine modifying the contract in Equation (2) so that $w(x)=\alpha+\beta(x-z)^{b}$, where $b$ is some positive variable. It is not difficult to show that the delegate can get more than $\left(r_{0}+r^{\prime} e\right)(s-z)+z$ when the contract is convex (i.e., $b>1$ ). This is not surprising, because it has been shown in the existing literature that the less risk-averse a bargainer is, the greater his bargaining power is. For example, Sobel (1981)

\footnotetext{
${ }^{20}$ For example, according to a consumer advocate Michael Royce, "Car salesmen are paid on a percentage of the profit of the sale. This percentage varies from dealership to dealership but usually runs in the $20 \%$ to $25 \%$ range." The "profit" here means sale price minus invoice cost, as we discussed in the Introduction. He gave the following example: "So if you buy a new car for, say, $\$ 300$ over the invoice cost, the salesman may earn only a $\$ 50$ to $\$ 75$ commission." Moreover, "According to a recent national survey, the average commission for car salesmen is $\$ 250$ per vehicle sold. The average selling price per vehicle is about $\$ 1,000$ over the invoice cost." The article is available on http://www.beatthecarsalesman.com/mailbag05.html.
} 
shows that if bargainers were allowed to choose their payoff functions among concave functions, choosing linear functions would be a dominant strategy. Haller and Holden (1997) present a simple example showing that convexifying the delegate's payoff function is always beneficial. Complicated convex contracts are seldom observed, however, because they suffer from several drawbacks. First, they are more likely subject to the agent's manipulations. ${ }^{21}$ Second, they are much less robust to changing environments. For example, if the potential buyer's valuation $s$ has a wide range, then a large $b$ means that the delegate's wage will have a very large variance, which can be costly in terms of implementation or when the delegate is even moderately riskaverse. Third, a convex contract may induce the agent to choose either zero effort or the greatest possible effort, which is non-realistic and uninteresting.

\subsection{Commitment Power of Agency Contracts}

So far in this paper we have assumed that the seller can commit to a minimum price with a delegate or a posted-price without a delegate. When the seller cannot commit to a posted price and does not hire a delegate, the Coase Conjecture implies that she would get zero profit in the limit in a dynamic bargaining setting (Gul, Sonnenschein and Wilson (1986)). A critical question in the delegation literature is whether and when a delegation contract can be credibly used as a commitment device. Here we briefly discuss some of the factors that may affect the credibility of using delegation contracts (i.e., a linear wage contract combined with a minimum price) as a commitment device in our context.

Recall that the commitment effect in our model comes from the minimum price only. As discussed before, given the delegate's effort $e$, neither the fixed wage nor the commission rate of the compensation contract directly affects the bargaining outcome. So the key to the question of credibility is whether the buyer can be convinced that the minimum price is indeed the limit of the delegate's discretion over price. How can the buyer be sure that the delegate is not lying about the minimum price? What is to prevent the delegate and the seller from rescinding the minimum price, especially when the buyer's valuation is just below it?

Not Perfectly Observable Contract. In some situations of delegated bargaining, delegation

\footnotetext{
${ }^{21}$ For example, if a contract has an incentive slope greater than one at some point, the agent will want to inflate the profit with his own money (or borrow from a bank) to get the extra reward.
} 
contracts are observable to the buyers. For example, in the case of car dealerships, car invoice prices are easily available to buyers from many car-related web sites. But if delegation contracts are not perfectly observable to the buyer, the delegate may have a tendency to claim that a minimum price is close to the buyer's valuation. But this tendency may destroy the credibility of using the minimum price as a commitment device. As a result, whether unobservable delegation contracts have any commitment value in our model is not clear. A thorough analysis would start by specifying the buyer's prior belief about the minimum price (whether it is set, and how much it is) and then study the bargaining game with such asymmetric information on the buyer's part. This is interesting to explore in future research, but is beyond the scope of this paper.

But if we still assume that the delegate knows the buyer's valuation, we can use the results from Gul and Sonnenschein (1988) to show that under fairly reasonable conditions the minimum prices can be revealed rather quickly in equilibrium, which implies that unobservable minimum prices still have considerable commitment power. The main problem, however, is that such bargaining models under asymmetric information often yield multiple equilibria. Moreover, if the delegate is not perfectly aware the buyer's valuation, things quickly become intractable.

Katz (1991), Fershtman and Kalai (1997), Corts and Neher (2003), Kockesen and Ok (2003), and many others have addressed the issue of whether unobservable contracts can still serve as a credible commitment device. Depending on the other party's belief, these papers find that unobservable contracts can still have commitment value when some equilibrium refinements are used. This suggests that our qualitative results should still be valid even when minimum prices are not perfectly observed by buyers.

Renegotiable Delegation Contracts. A related credibility issue arises if the seller and the delegate can renegotiate the delegation contract. ${ }^{22}$ In our model, renegotiation can be especially relevant if the delegate finds out that the buyer's valuation is below the minimum price. A Pareto improvement is readily available if the minimum price in the delegate's compensation contract is lowered. But if renegotiation is possible in such cases, then there is no compelling reason why it cannot be in any other cases.

To maintain the credibility of the minimum price, the seller and the delegate may rely on rep-

\footnotetext{
${ }^{22}$ See, e.g., Dewatripont (1988), Caillaud et al. (1995) and Bester and Sákovics (2001) for analysis of commitment effect when delegation contracts are renegotiable.
} 
utation effects (see discussions below) or other sorts of institutions. In the case of car dealerships, the dealer's invoice price (and other related contractual provisions between car manufacturers and car dealers) can be thought of an institutional innovation to maintain credibility with the help of car manufacturers. ${ }^{23}$

Reputation in Multi-Unit Sale. In situations such as car dealerships, the delegate is hired to sell the same products over time. Our model and our results extend easily to the case in which there are $N$ potential buyers with identical and independent distributions of valuations. On the credibility issue (which our model does not directly address), repeated sales may make it easier for the seller and the delegate to commit to a minimum price than a single-unit sale. When information about prices from past trades is available to later buyers (e.g., through word of mouth communication or consumer reports), the delegate and the seller may have incentives to stick to the minimum price despite short-term gains from trading with low-valuation buyers.

Reputation with Multiple Delegates. Similar reputation effects can arise when the seller hires multiple delegates to conduct sales (e.g., one person owns several dealerships, each of which is run by a manager). If the seller renegotiates with one manager, then it is hard not to renegotiate with other managers, which can reduce the total profit for the seller.

\footnotetext{
${ }^{23}$ Alternatively, car manufactures would simply sell cars to car dealerships at lower prices. It seems difficult to justify going through all the troubles of those contractual provisions (e.g., holdbacks and other incentives) if not for commitment purposes.
} 


\section{APPENDIX}

Proof of Proposition 1: Let us define $E[w(\hat{t}, x)]=\alpha(\hat{t})+\beta(\hat{t}) \int_{z(\hat{t})}^{\bar{s}}(x-z(\hat{t})) d G(s)$ and let $E[w(t, x)]$ be the same expectation replacing $\hat{t}$ with $t$. The type $t$ delegate's utility when he announces type $\hat{t}$ is

$$
U_{D}(\hat{t}, t)=E[w(\hat{t}, x)]-C(e, t)
$$

Consider a seller's effort recommendation $e(\hat{t})$. Suppose the delegate follows it. The incentive compatibility condition reduces to truth-telling only. The first-order condition with respect to the delegate's type announcement is

$$
\left.\frac{\partial U_{D}(\hat{t}, t)}{\partial \hat{t}}\right|_{\hat{t}=t}=0
$$

Let $U_{D}(t)=U_{D}(t, t)$ be the delegate's utility when he reports his true type. The total derivative of $U_{D}(t)$ with respect to his type report can be obtained from the Envelope Theorem as follows

$$
\left.\frac{d U_{D}(\hat{t}, t)}{d t}\right|_{\hat{t}=t}=\left.\frac{\partial U_{D}(\hat{t}, t)}{\partial \hat{t}}\right|_{\hat{t}=t}+\left.\frac{\partial U_{D}(\hat{t}, t)}{\partial t}\right|_{\hat{t}=t}=\left.\frac{\partial U_{D}(\hat{t}, t)}{\partial t}\right|_{\hat{t}=t}=-C_{t}(e(t), t)
$$

where the last equality comes from Equation (7). Since this is a total derivative the delegate's utility can be reconstructed by integrating this equation with respect to his type.

$$
U_{D}(t)=U_{D}(\underline{t})-\int_{\underline{t}}^{t} C_{t}(e(\nu), \nu) d \nu
$$

So, from Equations (7) (evaluated at the delegate's true type) and (8) we can solve for the wage schedule as follows

$$
E[w(t, x)]=U_{D}(t)+C(e(t), t)=U_{D}(\underline{t})-\int_{\underline{t}}^{t} C_{t}(e(\nu), \nu) d \nu+C(e(t), t)
$$

Plugging this wage schedule and the bargaining outcome (iii) into the seller's expected utility function (Equation (3)) gives

$$
E U_{P}=\int_{\underline{t}}^{\bar{t}}\left\{\int_{z(t)}^{\bar{s}}\left[z(t)+\left(r_{0}+r^{\prime} e\right)(s-z(t))\right] d G(s)-C(e(t), t)+\int_{\underline{t}}^{t} C_{t}(e(\nu), \nu) d \nu\right\} d F(t)-U_{D}(\underline{t})
$$

\footnotetext{
Next, integrating by parts the last term of the integral yields
} 


$$
\begin{aligned}
\int_{\underline{t}}^{\bar{t}} \int_{\underline{t}}^{t} C_{t}(e(\nu), \nu) d \nu d F(t) & =\left[-(1-F(t)) \int_{\underline{t}}^{t} C_{t}(e(\nu), \nu) d \nu\right]_{\underline{t}}^{\bar{t}}+\int_{\underline{t}}^{\bar{t}}\left[\frac{1-F(t)}{f(t)}\right] C_{t}(e(t), t) d F(t) \\
& =\int_{\underline{t}}^{\bar{t}}\left[\frac{1-F(t)}{f(t)}\right] C_{t}(e(t), t) d F(t)
\end{aligned}
$$

Note that if the seller ensures a type $\underline{t}$ a utility $U_{D}(\underline{t})=U_{0}$, the interim participation constraint is satisfied for all types. The reason is that the delegate's utility function (Equation (8)) is increasing in $t$ since $C_{t}$ is negative. Hence the seller should set $U_{D}(\underline{t})=U_{0}$. Using Equation $(10), U_{D}(\underline{t})=U_{0}$, and $\int_{z}^{\bar{s}} z d G(s)=z[1-G(z)]$, Equation (9) reduces to

$$
E U_{P}=\int_{\underline{t}}^{\bar{t}}\left\{\left(r_{0}+r^{\prime} e\right) \int_{z}^{\bar{s}}[s-z] d G(s)+z[1-G(z)]-C(e, t)+C_{t}(e, t) \frac{1-F(t)}{f(t)}\right\} d F(t)-U_{0}
$$

where the argument $(t)$ is suppressed in $e$ and $z$, and $z \in[\underline{s}, \bar{s}]$.

The seller maximizes $E U_{P}$ by choosing $e(t)$ and $z(t)$. By point-wise differentiation of Equation (11), and assuming interior solutions, $e^{*}(t)$ and $z^{*}(t)$ must satisfy the following first-order conditions: ${ }^{24}$

$$
\begin{aligned}
r^{\prime} \int_{z^{*}}^{\bar{s}}\left[s-z^{*}\right] d G(s) & =C_{e}\left(e^{*}, t\right)-\left[\frac{1-F(t)}{f(t)}\right] C_{e t}\left(e^{*}, t\right) \\
\left(1-r\left(e^{*}\right)\right)\left(1-G\left(z^{*}\right)\right) & =z^{*} g\left(z^{*}\right)
\end{aligned}
$$

which are Equations (4) and (5).

Now we check that the linear compensation contract under consideration indeed implements $e^{*}(t)$. The type $t$ delegate's utility when he reports $\hat{t}$, chooses $e$ and is paid according to contract (6) is

$$
\begin{aligned}
U_{D}(\hat{t}, e, t) & =\alpha^{*}(\hat{t})+\beta^{*}(\hat{t})\left(r_{0}+r^{\prime} e^{*}(\hat{t})\right) \int_{z^{*}(\hat{t})}^{\bar{s}}\left[s-z^{*}(\hat{t})\right] d G(s)-C(e, t) \\
& =C\left(e^{*}(\hat{t}), \hat{t}\right)+C_{e}\left(e^{*}(\hat{t}), \hat{t}\right)\left(e-e^{*}(\hat{t})\right)-\int_{\underline{t}}^{\hat{t}} C_{t}\left(e^{*}(\nu), \nu\right) d \nu-C(e, t)+U_{0}
\end{aligned}
$$

\footnotetext{
${ }^{24}$ We concentrate on interior solutions for $z(t)$. It is easy to see that $z^{*}$ must be less than $\bar{s}$, since $\partial E U_{P} / \partial z=$ $-\bar{s} g(\bar{s})<0$ at $z=\bar{s}$. A sufficient condition for $z>\underline{s}$ is that $1-r(\tilde{e}(t))>\underline{s} g(\underline{s})$, where $\tilde{e}(t)$ is the solution to Equation (4) with $z(t)=\underline{s}$.
} 
The first-order conditions for $e$ and $\hat{t}$ are the following:

$$
\begin{gathered}
\frac{\partial U_{D}(\hat{t}, e, t)}{\partial e}=C_{e}\left(e^{*}(\hat{t}), \hat{t}\right)-C_{e}(e, t)=0 \\
\frac{\partial U_{D}(\hat{t}, e, t)}{\partial \hat{t}}=\left[e-e^{*}(\hat{t})\right] \frac{d}{d \hat{t}} C_{e}\left(e^{*}(\hat{t}), \hat{t}\right)=0
\end{gathered}
$$

which are satisfied at $\hat{t}=t$ and $e=e^{*}(t)$. The second-order conditions for a maximum are satisfied. First, we have $\partial^{2} U_{D} / \partial e^{2}<0$. Second, from Equation (4),

$$
\begin{aligned}
\frac{d}{d t} C_{e}\left(e^{*}(t), t\right) & =r^{\prime} \frac{\partial \int_{z^{*}(t)}^{\bar{s}}\left[s-z^{*}(t)\right] d G(s)}{\partial z} \frac{\partial z^{*}}{\partial t}+C_{e t} \frac{d}{d t} \frac{1-F(t)}{f(t)}+C_{e t t} \frac{1-F(t)}{f(t)} \\
& =-r^{\prime}[1-G(z)] \frac{\partial z}{\partial t}+C_{e t} \frac{\partial}{\partial t} \frac{1-F(t)}{f(t)}+C_{e t t} \frac{1-F(t)}{f(t)}
\end{aligned}
$$

Proposition 2 shows that $z$ is non-increasing in type. Hence the first term of the equality is non-negative. The other two terms are also non-negative given the assumptions. Hence, the determinant of the second-order matrix is non-negative.

$$
\frac{\partial^{2} U_{D}(t, e, t)}{\partial e^{2}} \frac{\partial^{2} U_{D}(t, e, t)}{\partial t^{2}}-\left(\frac{\partial^{2} U_{D}(t, e, t)}{\partial e \partial t}\right)^{2}=-C_{e t}\left(e^{*}(t), t\right) \frac{d}{d t} C_{e}\left(e^{*}(t), t\right) \geq 0
$$

This is satisfied because $C_{e}\left(e^{*}(t), t\right)$ is non-decreasing in type.

Q.E.D.

Proof of Proposition 2: From the seller's expected payoff function in Equation (11), we can show that

$$
\begin{aligned}
\frac{\partial^{2} E U_{P}}{\partial e \partial(-z)} & =r^{\prime} \frac{\partial \int_{z}^{\bar{s}}[s-z] d G(s)}{\partial(-z)}=r^{\prime}[1-G(z)] \geq 0 \\
\frac{\partial^{2} E U_{P}}{\partial e \partial t} & =-C_{e t}\left(1-\frac{\partial}{\partial t} \frac{1-F(t)}{f(t)}\right)+\left[\frac{1-F(t)}{f(t)}\right] C_{e t t}(e, t) \geq 0 \\
\frac{\partial^{2} E U_{P}}{\partial(-z) \partial t} & =0
\end{aligned}
$$

Therefore, $E U_{P}(e,-z, t)$ is supermodular, and by the monotone comparative statics, $e(t)$ is non-decreasing in $t$ and $z$ is non-increasing in $t$.

Q.E.D. 
Proof of Corollary 1: First, $\beta^{*}(t)$ is non-decreasing in $t$ because

$$
\begin{aligned}
\frac{\partial \beta^{*}(t)}{\partial t} & =\frac{\int_{z^{*}(t)}^{\bar{s}}\left[s-z^{*}(t)\right] d G(s) \frac{\partial}{\partial t} C_{e}\left(e^{*}(t), t\right)-C_{e}\left(e^{*}(t), t\right) \frac{\partial}{\partial z}\left(\int_{z^{*}(t)}^{\bar{s}}\left[s-z^{*}(t)\right] d G(s)\right) \frac{\partial z}{\partial t}}{r^{\prime}\left(\int_{z^{*}(t)}^{\bar{s}}\left[s-z^{*}(t)\right] d G(s)\right)^{2}} \\
& =-\frac{\left[r^{\prime} \int_{z^{*}(t)}^{\bar{s}}\left[s-z^{*}(t)\right] d G(s)-C_{e}\left(e^{*}(t), t\right)\right]\left(1-G\left(z^{*}(t)\right) \frac{\partial z}{\partial t}\right.}{r^{\prime}\left(\int_{z^{*}(t)}^{\bar{s}}\left[s-z^{*}(t)\right] d G(s)\right)^{2}}+\frac{\left[C_{e t}\left(e^{*}(t), t\right) \frac{\partial}{\partial t} \frac{1-F(t)}{f(t)}+C_{e t t} \frac{1-F(t)}{f(t)}\right]}{r^{\prime} \int_{z^{*}(t)}^{\bar{s}}\left[s-z^{*}(t)\right] d G(s)} \\
& \geq 0
\end{aligned}
$$

Next, $\alpha^{*}(t)$ is non-increasing in type because

$$
\frac{\partial \alpha^{*}(t)}{\partial t}=-\frac{r\left(e^{*}(t)\right)}{r^{\prime}} \frac{\partial}{\partial t} C_{e}\left(e^{*}(t), t\right) \leq 0
$$

Q.E.D.

Proof of Corollary 2: Differentiating totally Equations (4) and (5) and using the particular form of $C(e, t)$ gives the following equations

$$
\begin{gathered}
-\mu d e-r^{\prime}\left(1-G\left(z^{*}\right)\right) d z=e^{*} d \mu+\left[\bar{t}-t+\frac{1-F(t)}{f(t)}\right] d \gamma \\
-r^{\prime}\left(1-G\left(z^{*}\right)\right) d e-\left[\left(1-r\left(e^{*}\right)\right) g\left(z^{*}\right)+\frac{\partial z^{*} g\left(z^{*}\right)}{\partial z}\right]=\left(1-G\left(z^{*}\right)\right) d r_{0}
\end{gathered}
$$

After some algebra we obtain that

$$
\begin{array}{ll}
\frac{d e^{*}}{d r_{0}}=\frac{r^{\prime}\left(1-G\left(z^{*}\right)\right)^{2}}{\Delta}>0 & \frac{d z^{*}}{d r_{0}}=\frac{-\mu\left(1-G\left(z^{*}\right)\right)}{\Delta}<0 \\
\frac{d e^{*}}{d \mu}=\frac{e \Delta_{z}}{\Delta}<0 & \frac{d z^{*}}{d \mu}=\frac{e^{*} r^{\prime}\left(1-G\left(z^{*}\right)\right)}{\Delta}>0 \\
\frac{d e^{*}}{d \gamma}=\frac{A \Delta_{z}}{\Delta}<0 & \frac{d z^{*}}{d \gamma}=\frac{A r^{\prime}\left(1-G\left(z^{*}\right)\right)}{\Delta}<0
\end{array}
$$

where $\Delta_{z}=-\left[\left(1-r\left(e^{*}\right)\right) g\left(z^{*}\right)+\frac{\partial z^{*} g\left(z^{*}\right)}{\partial z}\right]<0, \Delta=-\mu \Delta_{z}-r^{\prime 2}\left(1-G\left(z^{*}\right)\right)^{2}>0$ (this is the determinant of the second-order condition for effort and minimum price) and $A=\bar{t}-t+\frac{1-F(t)}{f(t)} \geq$ 0. 
From Equation (6), $d \beta^{*}=\mu\left(\int_{z^{*}}^{\bar{s}}\left(s-z^{*}\right) d G(s) d e+e^{*}\left(1-G\left(z^{*}\right)\right) d z\right) / r^{\prime}\left(\int_{z^{*}}^{\bar{s}}\left(s-z^{*}\right) d G(s)\right)^{2}$, and hence

$$
\begin{aligned}
& \frac{d \beta^{*}}{d r_{0}}=\frac{\mu\left(1-G\left(z^{*}\right)\right)^{2}\left(r^{\prime} \int_{z^{*}}^{\bar{s}}\left(s-z^{*}\right) d G(s)-\mu e^{*}\right)}{r^{\prime} \Delta\left(\int_{z^{*}}^{\bar{s}}\left(s-z^{*}\right) d G(s)\right)^{2}}>0 \\
& \frac{d \beta^{*}}{d \mu}=\frac{e^{*}\left[r^{\prime} \int_{z^{*}}^{\bar{s}}\left(s-z^{*}\right) d G(s) \mu \Delta_{z}+\mu e^{*}\left(1-G\left(z^{*}\right)\right)^{2} r^{\prime 2}\right]}{r^{\prime} \Delta\left(\int_{z^{*}}^{\bar{s}}\left(s-z^{*}\right) d G(s)\right)^{2}}<0 \\
& \frac{d \beta^{*}}{d \gamma}=\frac{A}{e^{*}} \frac{d \beta^{*}}{d \mu}<0
\end{aligned}
$$

Q.E.D.

\section{References}

[1] Baye, M., K. Crocker and J. Ju, 1996, "Divisionalization, Franchising, and Divestiture Incentives in Oligopoly," American Economic Review, 86, 223-236.

[2] Bester, H. and J. Sákovics, 2001, "Delegated Bargaining and Renegotiation," Journal of Economic Behavior and Organization, 45, 459-473.

[3] Binmore, K., A. Rubinstein and A. Wolinsky, 1986, "The Nash Bargaining Solution in Economic Modeling," RAND Journal of Economics, 17, 176-188.

[4] Cai, H., 2000, "Bargaining on Behalf of a Constituency," Journal of Economic Theory, 92, 234-273.

[5] Caillaud, B., B. Jullien and P. Picard, 1995, "Competing Vertical Structures: Precommitment and Renegotiation," Econometrica, 63, 621-646.

[6] Corts, K. and D. Neher, 2003, "Credible Delegation," European Economic Review, 47, 395-407.

[7] Crawford, V., 1982, "A Theory of Disagreement in Bargaining," Econometrica, 50, 607-637.

[8] Dewatripont, M., 1988, "Commitment Through Renegotiation-Proof Contracts with Third Parties," Review of Economic Studies, 55, 377-390. 
[9] Eskeldson, M., 1997, What Car Dealers Don't Want You to Know. Technews Publishing.

[10] Fershtman, C. and K. Judd, 1987a, "Equilibrium Incentives in Oligopoly," American Economic Review, 77, 927-940.

[11] Fershtman, C. and K. Judd, 1987b, "Strategic Incentive Manipulation in Rivalrous Agency," mimeo.

[12] Fershtman, C., K. Judd and E. Kalai, 1991, "Observable Contracts: Strategic Delegation and Cooperation," International Economic Review, 32, 551-559.

[13] Fershtman, C. and E. Kalai, 1997, "Unobserved Delegation," International Economic Review, 38, 763-774.

[14] Gal-Or, E., 1991a, "A Common Agency with Incomplete Information," RAND Journal of Economics, 22, 274-86.

[15] Gal-Or, E., 1991b, "Vertical Constraints with Incomplete Information," Journal of Industrial Economics, 39, 503-16.

[16] Gal-Or, E., 1992, "Vertical Integration in Oligopoly," Journal of Law, Economics and Organization, 8, 377-93.

[17] Gal-Or, E, 1995, "Correlated Contracts in Oligopoly," International Economic Review 36, 75-100.

[18] Gul, F. and H. Sonnenschein, 1988, "On Delay in Bargaining with One-sided Uncertainty," Econometrica, 57, 81-95.

[19] Gul, F., H. Sonnenschein and R. Wilson, 1986, "Foundations of Dynamic Monopoly and the Coase Conjecture," Journal of Economic Theory, 39, 155-190.

[20] Haller, H. and S. Holden, 1997, "Ratification Requirement and Bargaining Power," International Economic Review, 38, 825-851.

[21] Hermalin, B., 1992, "The Effects of Competition on Executive Behavior," RAND Journal of Economics, 23, 350-65. 
[22] Hermalin, B., 1995, "Heterogeneity in Organizational Form: Why Otherwise Identical Firms Choose Different Incentives for Their Managers," RAND Journal of Economics, 25, 518-37.

[23] Holmstrom, B., and P. Milgrom, 1987, "Aggregation and Linearity in the Provision of Intertemporal Incentives," Econometrica, 55, 597-619.

[24] Jensen, M., and K. J. Murphy, 1990, "Performance Pay and Top Management Incentives," Journal of Political Economy, 98, 225-264.

[25] Kahenmann, M., 1995, "A Model of Bargaining Between Delegates," Tel Aviv University, Working Paper No. 25-95.

[26] Katz, M., 1991, "Game-playing Agents: Unobservable Contracts as Precommitments," RAND Journal of Economics, 22, 307-328.

[27] Kockesen, L. and E. Ok, 2003, "Strategic Delegation By Unobservable Incentive Contracts," Review of Economic Studies, forthcoming.

[28] Laffont, J. and D. Martimort, 1997, "The Firm as a Multicontract Organization," Journal of Economics and Management Strategy, 6, 201-34.

[29] Laffont, J., and J. Tirole, 1986, "Using Cost Observation to Regulate Firms," Journal of Political Economy, 94, 614-641.

[30] Martimort, D., 1996, "Exclusive Dealing, Common Agency, and Multiprincipals Incentive Theory," RAND Journal of Economics, 27, 1-31.

[31] McAffe, R. P. and J. McMillan, 1987, "Competition for Agency Contracts," RAND Journal of Economics, 18, 296-307.

[32] Milgrom, P. and C. Shannon, 1994, "Monotone Comparative Statics," Econometrica, 62, $157-180$.

[33] Murphy, K.J., 1999, "Executive Compensation," O. Ashenfelter and D. Card, ed. Handbook of Labor Economics, New York: Elsevier, 2485-2563. 
[34] Muthoo, A., 1996, "A Bargaining Model Based on the Commitment Tactic," Journal of Economic Theory, 69, 134-152.

[35] Osborne, M. and A. Rubinstein, 1990, Bargaining and Market, Academic Press, San Diego, California.

[36] Rey, P. and J. Tirole, 1986, "The Logic of Vertical Restraints," American Economic Review, 76, 921-939.

[37] Rubinstein, A., 1982, "Perfect Equilibrium in a Bargaining Model," Econometrica, 50, 97109.

[38] Schelling, T., 1960, The Strategy of Conflict. New York. Oxford University Press.

[39] Sklivas, S., 1987, "The Strategic Choice of Managerial Incentives," RAND Journal of Economics, 18, 452-58.

[40] Sobel, J., 1981, "Distortion of Utilities and the Bargaining Problem," Econometrica, 49, 597-619.

[41] Vickers, J., 1985, "Delegation and the Theory of the Firm," Economic Journal, 95, 138-147.

[42] Wang, R., 1995, "Bargaining versus Posted-Price Selling," European Economic Review, 39, 1747-64. 